\title{
Clinicopathologic Features of Epithelial Ovarian Cancer
}

\author{
FASIF A SATTAR SHAHARYAR \\ Deparlmem of C'linical Oncologi: King Edward Medical College. Mayo hospital. Lahore. \\ correspondence to Prof. Shaharyar
}

Objectives: This retrospective study was conducted at the Clinical Oncology Department of Mayo Hospital with the objectives to find out the frequency of different clinicopathologic features and to see the pattern of treatment and its outcome. Patients and methods: From 2000 to 2004, 375 patients were seen at the Department of Clinical Oncology, Mayo hospital, Lahore. A proforma was designed to document the age, parity, histopathology, stage, grade, clinical features, and family history. The information was obtained from the medical record section. Stage was assigned according to FIGO staging system. All patients with histopathologically proven epithelial ovarian cancer were included. Results: Epithelial ovarian cancer constituted $8.4 \%$ of all female cancers. The median age at presentation was 51 years (range, 21 75 years). All patients were symptomatic before the diagnosis, with ascites being the most common single manifestation $(38.4 \%)$ and in patients with multiple signs and symptoms abdominal symptoms were most commonly seen $(71.5 \%)$. Median pre operative CA 125 level was $218 \mathrm{U} / \mathrm{ml}$. ). Optimal cytoreduction was seen in $36.5 \%$ only, and $63.5 \%$ patients presented after sub-optimal cytoreduction. Majority of the patients $(82.7 \%$ ) presented in late stages (III \& IV) and only 17.3 $\%$ in early stages (I\&II). Most common histopathologic type of invasive cancer was serous cystadenocarcinoma, seen in $247(72.4 \%)$ patients. Endometrioid tumors were seen in very few $(3.8 \%)$. High grade tumors were the most common. Most women were multiparous and only $16.5 \%$ were nulliparous. Post operative treatment primarily included cisplatin based combination chemotherapy. One hundred and twenty seven patients were re treated for recurrent or residual disease and 68 were referred for secondary cytoreduction and were given second line therapy subsequently. Conclusion: Epithelial ovarian cancer is not a silent disease, most patients are symptomatic and present in an advanced stage. In majority of the patients optimal cytoreduction is not achieved. Cystadenocarcinoma is the predominant histology and the endometrioid variety is seen only in few.

Key words: Epithelial ovarian cancer, cytoreduction, clinico-pathologic features.

Ovarian cancer is the third most common cancer in females in Pakistan. The age-standardized incidence rate is 9.6 and it constitutes $5.6 \%$ of all female cancers ${ }^{1}$. Ovarian cancer is the fifth most common malignancy of females in the United States and there it constitutes $4 \%$ of all female cancers $^{2}$. Globally it ranks as the $6^{\text {th }}$ common cancer in females. Majority of the ovarian cancers in adults are of epithelial origin

The likelihood of developing ovarian cancer increases with age. Most ovarian cancers occur in women over the age of 50 , with the highest risk in women over 70 years of age $\mathrm{e}^{2}$. Other factors associated with an increased risk of epithelial cancer include Caucasian race, nulliparity, early age of menarche, late age of menopause, personal history of breast cancer or a family history of either breast or ovarian cancer ${ }^{4.9}$. Multiparity and use of oral contraceptive pill is protective ${ }^{10.12}$. Tubal ligation, hysterectomy and breast feeding are also protective $e^{0.10 .13 .14}$. Studies on estrogen replacement therapy and use of talc give conflicting results ${ }^{10.15 .17}$. The role of diet and obesity in ovarian cancer is unsettled.

Hereditary ovarian cancer syndromes, include site specific ovarian cancer, breast-ovarian cancer, and the cancer family syndrome (Lynch syndrome II) ${ }^{18.19}$. Sitespecific ovarian and breast-ovarian cancer syndromes are related to two genetic susceptibility genes, BRCA I and BRCA II, which account for as many as $90 \%$ of hereditary ovarian cancers ${ }^{2(1)-21}$. The Lynch syndrome II describes hereditary nonpolyposis colorectal cancer associated with other cancers, in particular, endometrial and ovarian cancers, and is related to the mutations in the genes involved in DNA mismatch repair ${ }^{22-23}$.

Ninety five percent women have some non-specific symptoms before diagnosis, however, symptoms are vague and ill defined, therefore, majority of patients are diagnosed in an advanced stage ${ }^{24}$. Tumor marker CA 125 has $70 \%$ sensitivity, $98.6 \%$ specificity but has a high false positive rate and a low positive predictive value and therefore is not a useful test for mass screening ${ }^{25-27}$.

This retrospective study was conducted at the Clinical Oncology department of Mayo Hospital with the objective to find out the frequency of different clinicopathological features and to see the pattern of treatment and its outcome.

\section{Patients and methods:}

We conducted this retrospective study on ovarian cancer patients who presented to Mayo Hospital during the years 2000-2004. A proforma was designed to document the age, area of residence, parity, clinical features, histopathologic type, stage, grade, and family history. All this information was obtained from the medical record section. Clinical features were further analyzed by a careful review of medical histories and patients were identified as having either single or multiple symptoms. Multiple symptoms were divided into four different groups of abdominal, gastrointestinal, genitourinary and pain category. Abdominal category included mass, ascites and 
distension; gastrointestinal category included nausea, vomiting, lack of appetite, early satiety, and constipation; genitourinary category included irregular cycles, urinary frequency and dyspareunia; and pain category comprised of low backache, lower abdominal and generalized abdominal pain.

Stage was assigned according to the FIGO staging system. Histopathologic reports were re-evaluated for confirmation of type and grade of tumor. Histopathological classification system of WHO was used. We included all patients with histopathologically proven epithelial ovarian cancer. Patients with germ cell neoplasm and sex cord stromal tumors were excluded from this study.

\section{Results}

A total of 9220 cancer patients presented at Mayo Hospital from the year 2000 to 2004, out of which 4470 were female. Three hundred and seventy five patients $(8.4 \%)$ were of epithelial ovarian cancer. The median age at presentation was 51 years (range, 21-75). Majority of the patients $281(74.9 \%)$ were from urban areas. Clinical manifestations were evaluable in 360 patients. All these patients were symptomatic before the diagnosis. Only 125 $(34.7 \%)$ patients presented with a single symptom while majority of patients $235(65.3 \%)$ presented with multiple signs and symptoms. Ascites was the most common single manifestation seen in $48(38.4 \%)$ (Table- 1$)$. In patients with multiple signs and symptoms abdominal symptoms were present in 168(71.5\%) and gastrointestinal in 141(60 $\%)$. Genitourinary and pain category were less frequently seen (Table 2). Pre operative CA 125 measurement was available in 330 patients. Median level was $218 \mathrm{U} / \mathrm{ml}$ (Range. 14-5345).

Thirty patients $(8 \%)$ presented without debulking surgery. All other patients had primary cytoreductive or de bulking surgery. Optimal cytoreduction was achieved in $126(36.5 \%)$ and $219(63.5 \%)$ patients presented after sub-optimal cytoreduction and had residual disease of greater then one $\mathrm{cm}$ in diameter.

Four patients $(1.2 \%)$ had borderline ovarian tumors. Out of 341 patients with invasive cancer 282 ( $82.7 \%$ ) patients were seen in late stages (III \& IV) and only 59(17.3\%) in early stages (I\&II ) Table 3. Most common histopathologic type of invasive cancer was serous cystadenocarcinoma, seen in $247(72.4 \%)$ patients. Endometrioid tumors were seen in very few $(3.8 \%)$ ). (Table-4). Grade was not specified in majority of patients; however, grade IV tumors were commoner then others at the time of presentation (Table-5)

Family history of ovarian cancer was present in three cases and history of prior breast cancer in two cases. Most women were multiparous and only $62(16.5) \%$ were nulliparous.

Postoperative treatment and primary chemotherapy in 354 patients included combination chemotherapy with cisplatin and cyclophosphamide, cisplatin and gemcitabine, cisplatin and docetaxel and cisplatin and paclitaxel in $210(59.3 \%), 88(24.9 \%), 45(12.7 \%)$, and $11(3.1 \%)$ respectively. Average of 04 cycles of each was given. One hundred and twenty seven patients were retreated for recurrent or residual disease and 68 were referred for seconday cytoreduction and were given second line chemotherapy subsequently while remaining were treated with various drugs or hormones.

Table 1: Single Clinical Manifestation ( $n=125)$

\begin{tabular}{lll}
\hline & Percentage & \\
\hline Ascites & $48(38.4 \%)$ & \\
Mass abdomen & $34(27.21 \%)$ & \\
Nausea / vomiting & $23(18.4 \%)$ & \\
Menstrual irregularity & $11(8.8 \%)$ & $06(4.8 \%)$ \\
Constipation & & $03(2.4 \%)$ \\
Urinary frequency & & $03 \%$ \\
\hline
\end{tabular}

Table 2 Multiple Symptom Categories $(n=235)$

\begin{tabular}{ll}
\hline & Percentage \\
\hline Abdominal & $168(71.48 \%)$ \\
Gastrointestinal & $141(60.00 \%$ \\
Genitourinary & $74(31.5 \%)$ \\
Pain & $28(11.9 \%)$ \\
\hline
\end{tabular}

Table 3 FIGO Staging $(n=341)$

\begin{tabular}{ll}
\hline Stage & Percentage \\
\hline I & $13(3.8 \%)$ \\
II & $46(13.5 \%)$ \\
III & $202(59.2 \%)$ \\
IV & $80(23.5 \%)$ \\
\hline
\end{tabular}

Table 4 Histopathology Of Invasive Cancer $(n=341)$

\begin{tabular}{ll}
\hline & Percentage \\
\hline Serous cystadenocarcinoma & $247(72.4 \%)$ \\
Mocinous cystadenocarcinoma & $44(12.9 \%)$ \\
Endormetrioid carcinoma & $13(3.8 \%)$ \\
Clear cell carcinoma & $12(3.5 \%)$ \\
Malignant brenner tumor & $07(2.1 \%)$ \\
Undifferentiated carcinoma & $18(5.3 \%)$ \\
\hline
\end{tabular}

Table 5: Histopathologic Grade Of Invasive Cancer $(n=34$ I)

\begin{tabular}{ll}
\hline Grade & Percentage \\
\hline I & $18(5.3 \%)$ \\
II & $22(6.5 \%)$ \\
III & $48(14.1 \%)$ \\
IV & $66(19.4 \%)$ \\
Not specified & $187(54.8 \%)$ \\
\hline
\end{tabular}

\section{Discussion:}

The incidence of ovarian cancer varies according to the race and geographic location ${ }^{13}$. The highest rates are reported in USA and Canada. Most Asian countries are considered to have low rates. The age standardized incidence rate of 9.6 (per 100,000 population ) reported from a population based tumor registry in Karachi is higher then the rates of 4.7 of Kuwait, 4.3 from India and is closer to the incidence rate of 11.9 in $\mathrm{USA}^{28}$. In this hospital series it constitutes $8.4 \%$ of all female cancers and 
possibly reflects a higher disease burden then is often ytioted.

Median age at diagnosis in our patients is 51 years, whereas, it is generally higher in western population; 54 years for hereditary cancers and 61 for general population ${ }^{20}$

This early age at diagnosis could possibly be related to the shorter life expectancy of our population. Like rest of the world majority belongs to urban areas. An urban life style and environamental factors might be contributory. Furthermore. the breast feeding and multiparity in rural areas might be a contributory factor in reducing the incidence.

Tumor marker CA125 is not an adequate tool for screening ovarian cance ${ }^{25-27}$. Screening for ovarian cancer with CA125 or ultrasonography is not yet recommended. Under these circumstances the symptomatology of disease becomes more important, both for the clinicians and the patients as well. All of our patients were symptomatic prior to the diagnosis, and multiple symptoms were present in majority. It is mandatory that patients with such multiple symptoms be investigated further with a pelvic examination, ultrasonography and CA125 measurement. Omission of these investigations leads to the delay of diagnosis in symptomatic patients.

Optimal cytoreduction was achieved in $36.5 \%$ of our patients only. In fact a large proportion of patients in developed countries are still not receiving adequate surgical treatment because of incomplete srurgical staging ${ }^{30}$. The completeness of surgical procedure varies from $54 \%$ to $97 \%$ in different series ${ }^{31-32}$. The very low rate of optimal cytoreduction needs to be improved by improving the technique and skill of cytoreduction. Surgery by non gynecologic oncologists or non gynecologists and by low volume providers contributes to sub optimal cytoreduction ${ }^{3.34}$

It is well established that epithelial ovarian cancer presents at an advanced stage, and likewise in our series majority presented in late stages. Our Histopathologic pattern is distinctly different from the western studies. We see far less patients with endometrioid type of cancer $(3.8 \%)$ as compared to the reported frequency of about 10 $\%$ in western literature 35 . This possibly is related to the higher incidence of endometriosis in white cacusian females then other races ${ }^{36}$.

\section{Conclusion;}

Epithelial ovarian cancer is not a silent disease, most patients are symptomatic and present in an advanced stage. In majority of the patients optimal cytoreduction is not achieved. Cystadenocarcinoma is a predominant histology and endometrioid is seen only in few of our patient in contrast to western patients.

\section{References:}

1. Yasmin Burgari: Epidemiology of Cancer in Karachi (1995-1999), Karachi 2001.

2. American Cancer Society; Cancer Facts \& Figures 2004. National Home Office; American Cancer Society, Inc., 1599 Clifton road, NE, Atlanta. GA Pg 15

3. Bernard $W$ and Paul Kleihues, World Cancer Report: International Agency for Research on Cancer Press 2003. Lyon France pg 22()-221

4. Banks E, Beral V, Reeves G. The epidemiology of epithelial ovarian cancer: a review. Int J Gynecol Cancer 1997; 7:425

5. Whittemore, AS, R, Harris, J, Intyre. Characteristics relating to ovarian cancer risk: Collaborative analysis of 12 U.S. case control studies. II. Invasive epithelial ovarian cancers in white women. Am J Epidemiol 1992; 136: 1184

6. Whittemore, AS, R, Harris, J, Intyre. Characteristics relating to ovarian cancer risk: Collaborative analysis of 12 U.S. case control studies. IV. The pathogenesis of epithelial ovarian cancer. Collaborative ovarian cancer group. Am J Epidemiol 1992; 136: 1212

7. Schildkraut, JM, Thompson, WD. Familial ovarian cancer: a population based case-control study. Am J Epidemiol 1988; 128:456

8. Kerlikowske, K, Brown, JS, Grady, DG. Should women with familial breast cancer undergo prophylactic oophorectomy. Obstet Gynecol 1992: 80:700.

9. Bergfeldt, K, Rydh, B, Granath, F, et al. Risk of ovarian cancer in breast-cancer patients with a family history of breast or ovarian cancer: a population-based cohort study. Lancet 2002; 360:891.

10. Ness, RB, Grisso, JA, Cottreau, C, et al. Factors related to inflammation of the ovarian epithelium and risk of ovarian cancer. Epidemiology 2000; 11:111.

11. Titus-Ernstoff, L, Perez, K, Cramer, DW, et al. Menstrual and reproductive factors in relation to ovarian cancer risk. Br J Cancer 2001; 84:714

12. Hankinson, SE, Coldit/, GA, Hunter DJ, et al. A quantitative assessment of oral contraceptive use and risk of ovarian cancer. Obstet Gynecol 1992; 8():708.

13. Daly, M, Obrams, GI. Epidemiology and risk assessment for ovarian cancer. Semin Oncol 1998; 25:255.

14. Hankinson, SE, Hunter, DJ, Colditz GA, et al. Tubal ligation, hysterectomy and risk of ovarian cancer. JAMA 1993; $270: 2813$.

15. Rodriguez, C, Tatham, LM, Calle, EE, et al. Infertility and risk of fatal ovarian cancer in a prospective cohort of US women. Cancer, Causes Control 1998; 9:645.

16. Coughlin, SS, Giustozzi, A, Smith, SJ, Lee, NC. A metaanalysis of estrogen relacement therapy and tisk of epithelial ovarian cancer. J Clin Epidemiol 2000; 53:367.

17. Gertıg, DM, Hunter DJ, Cramer DW, et al. Prospectıve study of talc use and ovarian cancer. J Natl Cancer Inst 2000; $92: 249$

18. Lynch, HT, Watson, P, Bewtra, C, et al. Hereditary ovarian cancer. Heterogeneity in age at diagnosis. Cancer 1991: $67: 1460$

19. Mecklin, JP, Jarvinen, HJ. Tumor spectrum in cancer family syndrome (hereditary nonpolyposis colorectal cancer) Cancer 1991; 68:1109.

2). Boyd J. Specific keynote: Hereditary ovarian cancer: What we know. Gynecol Oncol 2003; 88:S8 
21. Ford D, Easton DF, Peto J estimates of the gene frequency of BRCAI and its contribution to breast and ovarian cancer incidence. Am J Hum Genet 1995;57:1457

22. Watson P, Lynch HT. Extracolonic cancer in hereditaryb nonpolyposis colorectal cancer.Cancer 1993; 71:677.

23. Aarnio, M, Mecklin, J-P, Aaltonen, LA, et al. Lifetime risk of different cancers in hereditary nonpolyposis colorectal cancer ( HNCC ) syndrome. Int J Cancer 1995; 64:430.

24. Goff, BA, Mandel, L, Muntz, HG, Melancon, CH. Ovarian carcınoma diagnosis [In process citation]. Cancer 2000; $89: 2008$

25. Zurawski VR, Orgeseter H, Andersen A, et al Elevated serum Ca 125 level ptior to diagnosis of ovarian neoplasia; Relevance for early detection of cancer. Int $\mathrm{J}$ cancer 1988:42:677

26. EinhornN, Sjovall K, Knapp RC et al. prospective evaluation of CA 125 levels for the early detection of ovarian cancer. Obstet Gynecol 1992;80:14

27. Jacob I. Davies AP Bridge J et al. prevalence screening for ovarian cancer in postmenopausal woman by CA 125 measurement and ultrasonography. BMJ 1993:306:1030

28. Parkin DM, whelam SI, Ferley J Raymond I.and Young J. Cancer incidence in five continents Vol VII IARC scientific publication No.143(1997)
29. Piver MS Hereditary ovarian cancer. Gynecol Oncol 2002;85:9

30. 30. David M Gershensen. Advances in the management of early stage epithelial ovarian cancer, American society of Clinical Oncology, 2001 education Book. 462-3

31. 31. McGowan 1, Lesher LP Norris HJ et al: Misstaging of ovarian cancer. Obstet Gynecol 1985,$65 ; 568$

32. 32. Trimbos JB, Schueler JA Vanlent M Et Al. Reasons for incomplete surgical staging in early ovarian carcinoma. Gynecol Oncol 1990 57; 374-77

33. Petıgnat, $P$, Vajda D,Joris F. Obrist R, Surgical management of epithelial ovarian cancer at community hospitals. A population based study. J surg Oncol 2000;75:19

34. Elit L, Bondy SJ, Paszat L et al. Outcomes in surgery for ovarian cancer.Gynecol Oncol 20(2;;87;260s

35. Scully, RE, Young RH,Clement PB, Endometrioid tumors In: Tumors of Ovary, Maldeveloped Gonads, Fallopian Tubes , and Broad Ligament, Armed Forces Institute of Pathology Washington DC 1998 p 107

36. Kistner RW .endometriosis and infertility. In; behrman SJ \& Kistner RW(eds) Progress in infertility. Boston ,MA. Little brown $\mathrm{p}$ 345-64 